Article

\title{
Comparative Study on Surface Structure, Electronic Properties of Sulfide and Oxide Minerals: A First-Principles Perspective
}

\author{
Weiyong Cui ${ }^{1}{ }^{\mathbb{D}}$, Yibing Zhang ${ }^{2}$, Jianhua Chen ${ }^{1,3,4, *}$, Cuihua Zhao ${ }^{3}$, Yuqiong $\mathrm{Li}^{3,4}$, Ye Chen ${ }^{3,4}$ \\ and Ming-Hsien Lee ${ }^{5}$ \\ 1 College of Chemistry and Chemical Engineering, Guangxi University, Nanning 530004, China; \\ wei_yung@163.com \\ 2 Guizhou Daliang Zinc Industry Co., Ltd., Duyun 558000, China; zybflad@163.com \\ 3 School of Resources, Environment and Materials, Guangxi University, Nanning 530004, China; \\ xiaocui2000110@163.com (C.Z.); lyq198205@163.com (Y.L.); fby18@126.com (Y.C.) \\ 4 Guangxi Key Laboratory of Processing for Non-ferrous Metal and Featured Materials, Guangxi University, \\ Nanning 530004, China \\ 5 Department of Physics, Tamkang University, New Taipei 25137, China; mhslee@mail.tku.edu.tw \\ * Correspondence: jhchen@gxu.edu.cn
}

Received: 17 April 2019; Accepted: 18 May 2019; Published: 28 May 2019

\begin{abstract}
First-principle calculations were used to investigate the surface structure and electronic properties of sulfide (pyrite, galena, and sphalerite) and oxide minerals (hematite, cerussite, and smithsonite). Surface relaxation and Femi energy, as well as projected DOS, are considered. Results show that the surface atoms of the sulfide minerals are more susceptible and more easily affected by the fracture bonds. The sulfide surfaces possess higher chemical potential than the corresponding oxide surfaces, and are more likely to be electron donors in reactions. The S 3p states are the mainly contributing states in the sulfide surface, while that in the oxide surface are $\mathrm{O} 2 \mathrm{p}$ states. The bonds of the sulfide surface have more covalent features and that of the oxide surface are ionic interactions. The O-M ( $\mathrm{M}$ represents $\mathrm{Fe}, \mathrm{Pb}$ or $\mathrm{Zn}$ ) bonds are more stable, as the DOS of the oxide surfaces distribute in the lower energy range.
\end{abstract}

Keywords: sulfide minerals; oxide minerals; surface electronic properties; density functional theory (DFT)

\section{Introduction}

Flotation is the most important and versatile mineral separation technique, which provides raw materials for our metallurgical and chemical industries [1]. For the nonferrous metals industry, flotation is an indispensable technique and usually used to enrich minerals, such as lead and zinc minerals. Comparatively speaking, the flotation operation of sulfide minerals is mature and has been well applied in plants around the world. The oxide minerals flotation is more difficult and complex than that of the corresponding sulfide minerals due to the surface hydrophilicity and electrostatic interaction [2]. However, the condition has become much more complicated with the depletion of the easy separation sulfide ore resources and the increasingly stringent environmental costs.

It is not a new topic that different surface properties lead to significant differences in flotation behaviors. The investigations about surface structure and properties of sulfide and oxide minerals are not rare, and corresponding papers include ultraviolet photoelectron spectroscopy (UPS) [3,4], Raman spectroscopy [5], scanning tunneling microscopy (STM) [3,6], time of flight secondary ion mass spectrometry, (ToF-SIMS) [6,7], x-ray photoelectron spectroscopy (XPS) [8-11], DFT studies [8,9,12-14], 
etc. Recently, reports with density functional theory method (DFT) triggered intense research in this area. G. U. von Oertzen and W. M. Skinner found that the quantum chemical simulation predicts an S $2 p$ core level shift of $0.69 \mathrm{eV}$ between the $S$ bulk and $S$ surface dimers, in good agreement with the $0.6 \mathrm{eV}$ found in XPS measurements [15]. A series of studies by Chen et al. confirmed that the lattice defects in sulfide minerals surface have significant effect on the properties of flotation [16-21]. Cong Han et al. found that the $\mathrm{O}$ atom on the hemimorphite (110) surface exhibits stronger ability on impeding the collector bond with the $\mathrm{Zn}$ atoms than that on the smithsonite (101) surface [13]. The research by Feng et al. showed that the active sites on the cerussite (110) surface are Pb atoms, which mainly contribute by the $\mathrm{Pb} 6 \mathrm{p}$ orbital [9]. However, a comprehensive research about the different structure and electronic properties of sulfide and oxide minerals surfaces has not been conducted.

As the most common and important minerals, lead, zinc, and iron ore widely exist in various sulfide and oxide minerals, which are usually found in mixtures or in combination with other minerals, and their nature differences have troubled us for many years. In this paper, the comparative study of sulfide and oxide minerals surface is considered, and three groups of representative mineral surface models (pyrite (100) and hematite (001) surfaces, galena (100) and cerussite (110) surfaces, as well as sphalerite (110) and smithsonite (101) surfaces) are chosen [22-26]. The surface relaxation, Femi energy and projected density of states (projected DOS) are discussed. It is expected that this research is of high interest for understanding the surface structure and electronic properties of sulfide and oxide minerals, and providing the theoretical basis for surface interaction.

\section{Computational Methods and Models}

\subsection{Computational Methods}

All calculations were performed using the density-functional theory (DFT) with Cambridge Serial Total Energy Package [27]. Ultra-soft pseudo-potential was used to describe electron-ion interactions. The exchange correlation functional used in pyrite and smithsonite models was GGA-PBE and GGA-PW91 in hematite and galena models, and GGA-WC and GGA-RPBE in cerussite and sphalerite models, respectively. The plane-wave cutoff energy of $280 \mathrm{eV}$ for pyrite, $220 \mathrm{eV}$ for hematite and galena, $260 \mathrm{eV}$ for cerussite and smithsonite, and $285 \mathrm{eV}$ for sphalerite were used throughout. Monkhorst-Pack k-point sampling density for pyrite and galena was $2 \times 2 \times 1$ mesh, $1 \times 1 \times 1$ for hematite, cerussite, and smithsonite, and $2 \times 3 \times 1$ for sphalerite. The Hubbard $U$ value of $7.5 \mathrm{eV}$ was adopted, and the spin-polarized in the pyrite and hematite models was chosen. The convergence tolerances for geometry optimization calculations were set to the maximum displacement of $0.002 \AA$, the maximum force of $0.05 \mathrm{eV} \cdot \AA^{-1}$, the maximum energy change of $2.0 \times 10^{-5} \mathrm{eV} \cdot \mathrm{atom}^{-1}$, and the maximum stress of $0.1 \mathrm{GPa}$, and the SCF convergence tolerance was set to be $2.0 \times 10^{-6} \mathrm{eV} \cdot \mathrm{atom}^{-1}$. Valence electron configurations considered in the research were $\mathrm{O} 2 \mathrm{~s}^{2} 2 \mathrm{p}^{4}, \mathrm{C} \mathrm{s} 2 \mathrm{p}^{2}, \mathrm{~S} 3 \mathrm{~s}^{2} 3 \mathrm{p}^{4}, \mathrm{Fe} 3 \mathrm{~d}^{6} 4 \mathrm{~s}^{2}$, $\mathrm{Pb} 6 \mathrm{~s}^{2} 6 \mathrm{p}^{2}$, and $\mathrm{Zn} 3 \mathrm{~d}^{10} 4 \mathrm{~s}^{2}$. The vacuum thickness in the surfaces was 10 angstroms, which could essentially meet the calculation.

\subsection{Computational Models}

The bulk models were optimized, and the results are in good agreement with the experimental results (see Table 1). The surface models were cleaved from the corresponding optimized bulk models and the most stable surface models were chosen. 
Table 1. The comparison between the lattice parameters of the optimized model and the experimental results of the bulk.

\begin{tabular}{|c|c|c|c|c|c|c|}
\hline \multirow{2}{*}{ Minerals } & \multicolumn{3}{|c|}{ Experimental Value } & \multicolumn{3}{|c|}{ Calculated Value (\% Difference) } \\
\hline & $\mathrm{a} / \AA ̊$ & b/Å & c/Å & $\mathrm{a} / \AA ̊ \AA$ & $\mathbf{b} / \AA$ & c/Å \\
\hline pyrite & 5.428 & 5.428 & 5.428 & $5.407(0.39 \%)$ & $5.407(0.39 \%)$ & $5.407(0.39 \%)$ \\
\hline hematite & 5.038 & 5.038 & 13.772 & $5.109(1.41 \%)$ & $5.109(1.41 \%)$ & $13.970(1.49 \%)$ \\
\hline galena & 5.914 & 5.914 & 5.914 & $5.832(1.39 \%)$ & $5.832(1.39 \%)$ & $5.832(1.39 \%)$ \\
\hline cerussite & 5.182 & 8.495 & 6.144 & $5.194(0.23 \%)$ & $8.50(0.06 \%)$ & $6.17(0.42 \%)$ \\
\hline sphalerite & 5.409 & 5.409 & 5.409 & $5.326(1.53 \%)$ & $5.326(1.53 \%)$ & $5.326(1.53 \%)$ \\
\hline smithsonite & 4.653 & 4.653 & 4.653 & $4.712(1.27 \%)$ & $4.712(1.27 \%)$ & $4.712(1.27 \%)$ \\
\hline
\end{tabular}

As shown in Figure 1a, pyrite (100) surface with twelve atomic layers is constructed and the coordination numbers of the exposed Fe and $\mathrm{S}$ atoms are five and three, respectively. Slab model with 18 atomic layers of hematite (001) surface is shown in Figure 1b. Each Fe atom of the surface coordinates with three adjacent $\mathrm{O}$ atoms, and the exposed $\mathrm{O}$ atom connects with the nearest three Fe atoms. Figure 1c shows the slab model of six atomic layers of galena (100) surface. The $\mathrm{Pb}$ atom of the surface bond with five $S$ atoms, and the coordination number of the outmost $S$ atom is also five. Figure $1 \mathrm{~d}$ presents the 12 atomic layers of cerussite (110) surface, and the central $\mathrm{Pb}$ atom has a coordination number of four, while the $\mathrm{O}$ atom coordinates with adjacent four $\mathrm{Pb}$ atoms. As shown in Figure 1e, a sphalerite (110) surface with 10 atomic layers is built and each exposed $\mathrm{Zn}$ (S) coordinates with adjacent three $S$ (Zn). For the smithsonite (101) surface (see Figure 1f), the exposed outer Zn atom coordinates with five $\mathrm{O}$ atoms and the $\mathrm{O}$ atom has a coordination number of two.

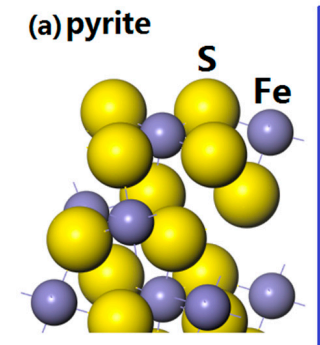

(b) hematite

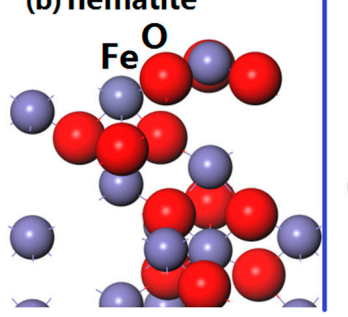

(c) galena

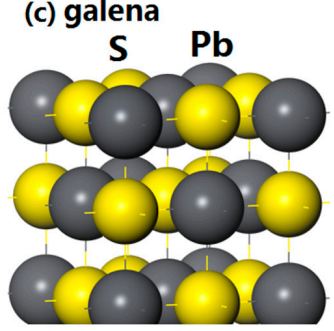

(d) cerussite

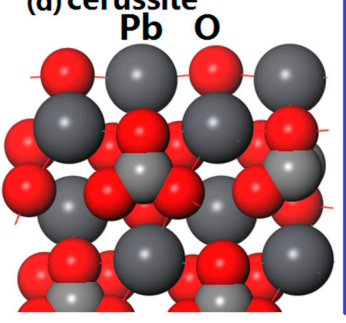

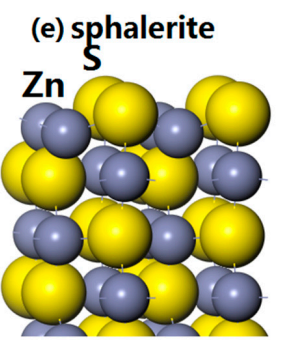

(f) smithsonite

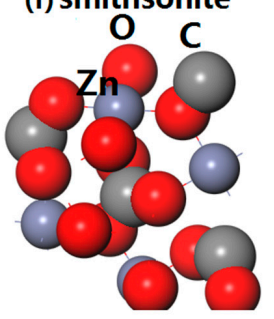

Figure 1. Slabs of represent minerals surfaces: (a) Pyrite (100) surface; (b) hematite (001) surface; (c) galena (100) surface; (d) cerussite (110) surface; (e) sphalerite (110) surface; (f) smithsonite (101) surface.

\section{Results and Discussions}

\subsection{Surface Relaxation}

Surface atoms will rearrange themselves spontaneously when a new surface is cleaved, and this has been confirmed in many reports [28-30]. The atom displacements of different surfaces are presented in Table 2.

For the pyrite (100) surface, the Fe and S atoms converge heavily toward the bulk with the displacements of $-4.83 \mathrm{pm}$ and $-8.72 \mathrm{pm}$ in the $z$-direction. Meanwhile, the opposite level displacements 
indicate that the two atoms move away from each other in the $x$-y plane. Atomic displacements of the hematite (001) surface are more complex than that of the pyrite (100) surface. The movements of $\mathrm{O}$ atoms are $-10.82 \sim 8.75 \mathrm{pm}$ and $-4.17 \sim 10.42 \mathrm{pm}$ in the $x$ and $y$ directions. The Fe mainly shows convergence along the $z$ direction with the shift of $-55.03 \mathrm{pm}$, which corresponds to the fact that the three broken bonds of the Fe atom are $z$-axis of rotation.

Interestingly, the main displacement of atoms in the galena (100) surface is from the $z$ direction, which is related to the unique crystal structure and the broken bonds along the $z$-direction. The corresponding values of $\mathrm{S}$ and $\mathrm{Pb}$ atoms are $20.56 \mathrm{pm}$ and $15.24 \mathrm{pm}$, respectively, which confirms that the severe interlayer atomic interactions and reconstructions occur in the galena (100) surface. Although there are serious bonds breaking in the cerussite (110) surface and the coordination number of $\mathrm{Pb}$ is reduced from 7 to 4 , the displacements of the $\mathrm{Pb}$ and $\mathrm{O}$ atoms are rather small and no apparent surface reconstruction is found, implying that the interaction of the $\mathrm{O}-\mathrm{Pb}$ bond is very strong.

For the sphalerite (110) surface, serious reconstruction can be seen, and the $\mathrm{Zn}$ and $\mathrm{S}$ atoms are shifted heavily in three-dimensional space. Atomic movement of the $S$ and $\mathrm{Zn}$ is as large as $44.20 \mathrm{pm}$ and $-22.91 \mathrm{pm}$ in $z$-direction, while that along the $x$ and $y$ directions also reach about 10 pm respectively, indicating that the S-Zn bond is greatly affected in the (110) surface. In the smithsonite (101) surface, the displacement of each atom is very small and cannot cause remarkable change, though there exists small shift in the surface.

Table 2. Atomic displacements of the minerals surface.

\begin{tabular}{ccccc}
\hline \multirow{2}{*}{ Minerals } & Atoms & \multicolumn{3}{c}{ Displacement/pm } \\
\cline { 3 - 5 } & & $\Delta x$ & $\Delta y$ & $\Delta z$ \\
\hline \multirow{2}{*}{ Pyrite (100) } & $\mathrm{S}$ & -2.77 & -6.82 & -4.83 \\
& $\mathrm{Fe}$ & 3.82 & 4.28 & -8.72 \\
\hline \multirow{2}{*}{ Hematite (001) } & $\mathrm{Fe}$ & 0.23 & 0.04 & -55.03 \\
& $\mathrm{O}$ & $-10.82 \sim-8.75$ & $-4.17 \sim-10.42$ & $-1.63 \sim-0.96$ \\
\hline \multirow{2}{*}{ Galena (100) } & $\mathrm{S}$ & 0.00 & 0.00 & 20.56 \\
& $\mathrm{~Pb}$ & 0.00 & 0.00 & 15.24 \\
\hline \multirow{2}{*}{ Cerussite (110) } & $\mathrm{O}$ & $-0.13 \sim-0.05$ & $-0.17 \sim-0.15$ & $-0.28 \sim-0.25$ \\
& $\mathrm{~Pb}$ & $0.04 \sim 0.09$ & $0.00 \sim 0.05$ & $-0.43 \sim-0.20$ \\
\hline \multirow{2}{*}{ Sphalerite (110) } & $\mathrm{S}$ & 7.20 & -8.30 & 44.20 \\
& $\mathrm{Zn}$ & -12.45 & -11.64 & -22.91 \\
\hline \multirow{2}{*}{ Smithsonite (101) } & $\mathrm{O}$ & 0.04 & 2.24 & 3.07 \\
& $\mathrm{O}$ & 1.77 & -1.24 & 1.20 \\
& $\mathrm{Zn}$ & -1.59 & 1.46 & -2.67 \\
\hline
\end{tabular}

\subsection{Femi Energy}

The Femi level shows the filling capacity of electrons, which often represents electron or hole chemical potentials, and can be defined as Equation (1):

$$
E_{f}=\mu=\left(\frac{\partial G}{\partial N}\right)_{T, p}
$$

where $\mu$ represents chemical potentials, $G$ is the Gibbs free energy, $N$ refers to the sum of the electrons of the whole system, and $T$ and $p$ represent temperature and pressure of the system, respectively.

The Femi level can reveal the ability of redox of the microsystem and reports show it can be well agreement with standard potential [31]. The higher Fermi energy system is more likely to transfer electrons and lower its Femi level to make the system more stable. As shown in Table 3, the Femi levels of pyrite (100) surface and hematite (001) surface are $0.3687 \mathrm{eV}$ and $-2.469 \mathrm{eV}$, respectively, which means that the pyrite (100) surface has higher chemical potential, and the result is consistent with 
the measurement of redox potential [32]. For the galena and cerussite system, the Femi energy of the galena (100) surface is $3.957 \mathrm{eV}$ and the corresponding value of the cerussite (110) surface is $-0.881 \mathrm{eV}$, that is, cerussite (110) surface is not as easy to transfer electrons as galena (100) surface, which was proven by Herrera-Urbinaa et al. with the pulp redox potential research [33]. Meanwhile, the Femi energy of the smithsonite (101) surface is also lower than that of the sphalerite (110) surface, indicating that the sphalerite surface has advantage as electron donors in chemical reaction, and this has been reported in many papers [34,35].

Table 3. The calculated Femi level of the minerals surface.

\begin{tabular}{cc}
\hline Surface & /eV \\
\hline Pyrite (100) & 0.3687 \\
Hematite (001) & -2.469 \\
\hline Galena (100) & 3.9567 \\
Cerussite (110) & -0.881 \\
\hline Sphalerite (110) & 1.2051 \\
Smithsonite (101) & -1.047 \\
\hline
\end{tabular}

\subsection{Surface Electronic Structure}

\subsubsection{Surface Properties of Pyrite (100) and Hematite (001) Surfaces}

The projected DOSs of S and Fe atoms in the pyrite (100) surface are presented in Figure 2. For the $\mathrm{S}$ center, the $\mathrm{S}-\mathrm{Fe}$ broken bond shows the largest component along the $z$-direction. Strong splits occur in the $S 3 p$ states, the $3 p_{x}, 3 p_{y}$, and $3 p_{z}$ states are rather different. The $3 p_{z}$ state has more distributions in the upper valence band, and its peaks at $-2.25 \mathrm{eV},-0.81 \mathrm{eV}$, and $-0.12 \mathrm{eV}$ are much higher. In the $\mathrm{Fe}$ center, the Fe $3 p_{x}, 3 p_{y}$, and $3 p_{z}$ are also different, and the $3 p_{z}$ state possesses sharp peaks at $0.76 \mathrm{eV}$, $4.88 \mathrm{eV}$, and $5.61 \mathrm{eV}$. The Fe $3 \mathrm{~d}$ states are divided into three groups, the $3 \mathrm{~d}_{\mathrm{x}}{ }^{2}-\mathrm{y}^{2}$, the $3 \mathrm{~d}_{\mathrm{z}}{ }^{2}$, and the $3 d_{x y}-3 d_{x z}-3 d_{y z}$ states. The $3 d_{x y}-3 d_{x z}-3 d_{y z}$ states are slightly split below Femi level and dominate the VBM, while the CBM are mainly contributed by $3 d_{z}{ }^{2}$ state. The $3 d_{x}{ }^{2}-y^{2}$ state is not split, however, the $3 \mathrm{~d}_{\mathrm{z}}{ }^{2}$ states has more distributions near Femi level, which is proven by the fact that there has high activity along $z$-direction in the dangling bond.

The overlaps between $S$ and Fe atoms are mainly from the contribution of $S 3 p$ and Fe $3 p, 3 d$ states. The bonding interactions are in the range of -7.5 to $-1.50 \mathrm{eV}$, which is contributed by $\mathrm{S} 3 \mathrm{p}\left(3 \mathrm{p}_{\mathrm{x}}\right.$, $3 p_{y}$ and $3 p_{z}$ ) and $\mathrm{Fe} 3 d_{x}{ }^{2}-y^{2}, 3 d_{z}{ }^{2}$, as well as $3 d_{x y}$ states. Significant antibonding areas are found near Femi level, and the interaction of $S 3 p_{z}$ and $F e 3 d_{x y}, 3 d_{x z}$, and $3 d_{y z}$ states are very strong in the range from -1.25 to $0 \mathrm{eV}$, while the mixings of the $\mathrm{S} 3 \mathrm{~s}, 3 \mathrm{p}$, and $\mathrm{Fe} 3 \mathrm{p}_{\mathrm{z}}, 3 \mathrm{~d}_{\mathrm{z}}{ }^{2}$, and $3 \mathrm{~d}_{\mathrm{xz}}$ states are in the range from 0.37 to $1.50 \mathrm{eV}$. Meanwhile, complex mixings are found in the conduction band areas far away from Femi level.

Figure 3 shows the projected DOSs of $\mathrm{O}$ and Fe atoms for hematite (001) surface. The O $2 \mathrm{p}$ states show obvious localization, and can be divided into two parts, the $2 p_{x}, 2 p_{y}$ states and $2 p_{z}$ state. The $2 p_{x}$, $2 p_{y}$ states are slightly disturbed and their curves seem to be similar, while the $2 p_{z}$ state is heavily split and its peak at $-5.5 \mathrm{eV}$ is sharp. There are three $\mathrm{O}-\mathrm{Fe}$ bonds broken in the Fe atom and the interactions of the other $\mathrm{O}-\mathrm{Fe}$ bonds become strong. As shown in Figure $3 b$, the Fe $3 p_{z}$ state is split heavily below the Femi level and shows apparent difference with the other two $3 p$ states in the range from -7.0 to $-3.0 \mathrm{eV}$. The octahedron field is destroyed, and the $3 \mathrm{~d}$ states are divided into three parts (Figure $3 \mathrm{c}, \mathrm{d}$ ), the $3 d_{x-y}{ }^{2}$ and $3 d_{x y}$ states, the $3 d_{x z}$ and $3 d_{y z}$ states, and the $3 d_{z}{ }^{2}$ state. The $3 d_{x}{ }^{2}-y^{2}$ and $3 d_{x y}$ states mainly distribute in high energy with the peaks at $-9.3 \mathrm{eV},-8.85 \mathrm{eV},-5.6 \mathrm{eV}$, and $-4.45 \mathrm{eV}$, the $3 \mathrm{~d}_{\mathrm{xz}}$ and $3 \mathrm{~d}_{\mathrm{yz}}$ states shows a slight split and their peaks are mainly in the range from -9.5 to $-4.0 \mathrm{eV}$, while the $3 \mathrm{~d}_{\mathrm{z}}{ }^{2}$ state is split heavily and its curve is in lower energy with remarkable peaks at $-9.65 \mathrm{eV},-7.30 \mathrm{eV}$, and $-6.5 \mathrm{eV}$. 


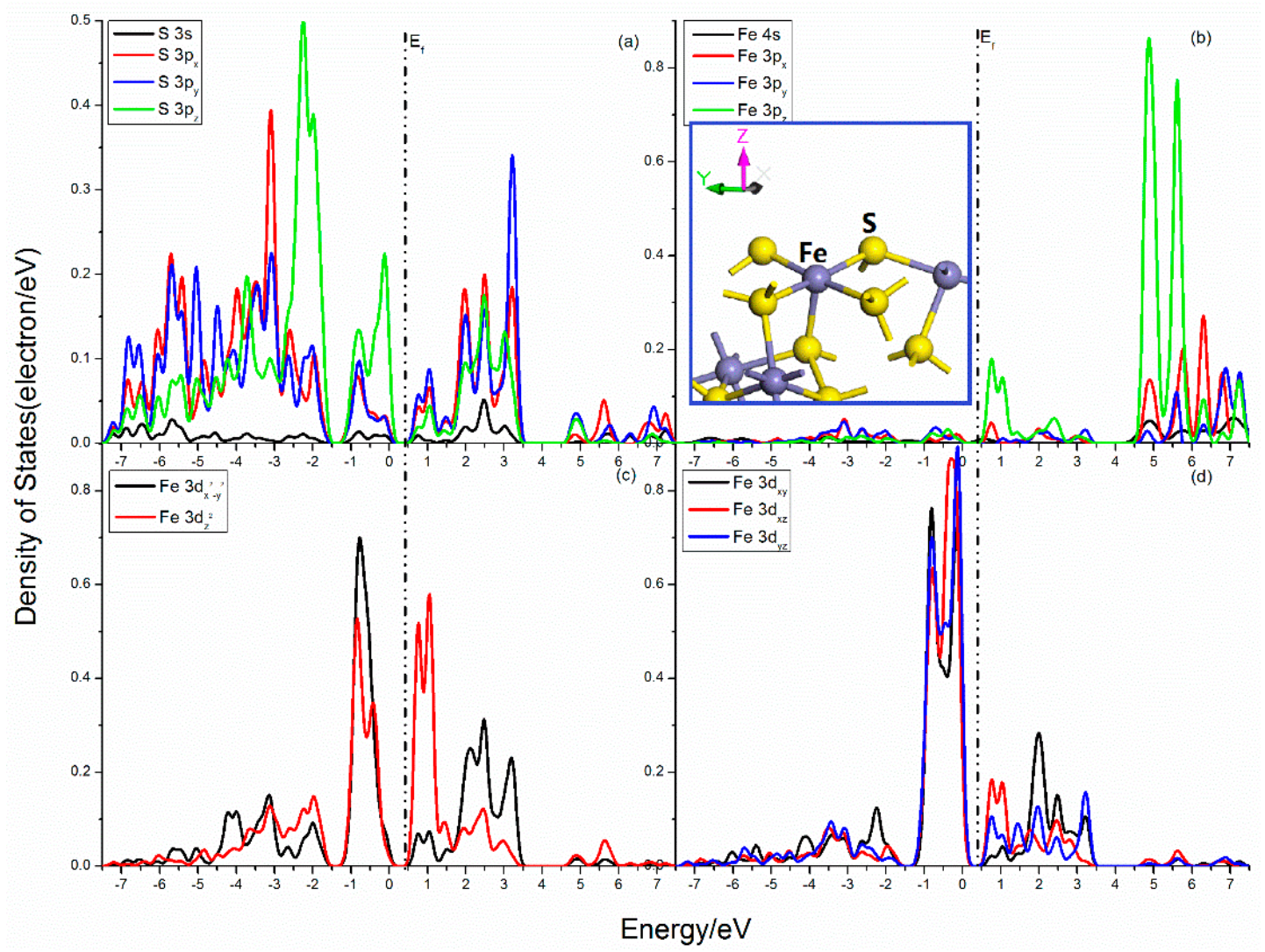

Figure 2. Projected DOSs of $S$ and Fe atoms of pyrite (100) surface: (a) $S 3 s, 3 p_{x}, 3 p_{y}$ and $3 p_{z}$ states; (b) Fe $4 \mathrm{~s}, 3 \mathrm{p}_{\mathrm{x}}, 3 \mathrm{p}_{\mathrm{y}}$ and $3 \mathrm{p}_{\mathrm{z}}$ states; (c) Fe $3 \mathrm{~d}_{\mathrm{x}}{ }^{2}-\mathrm{y}^{2}$ and $3 \mathrm{~d}_{\mathrm{z}}{ }^{2}$ states; (d) Fe $3 d_{\mathrm{xy}}, 3 \mathrm{~d}_{\mathrm{xz}}$ and $3 \mathrm{~d}_{\mathrm{yz}}$ states.

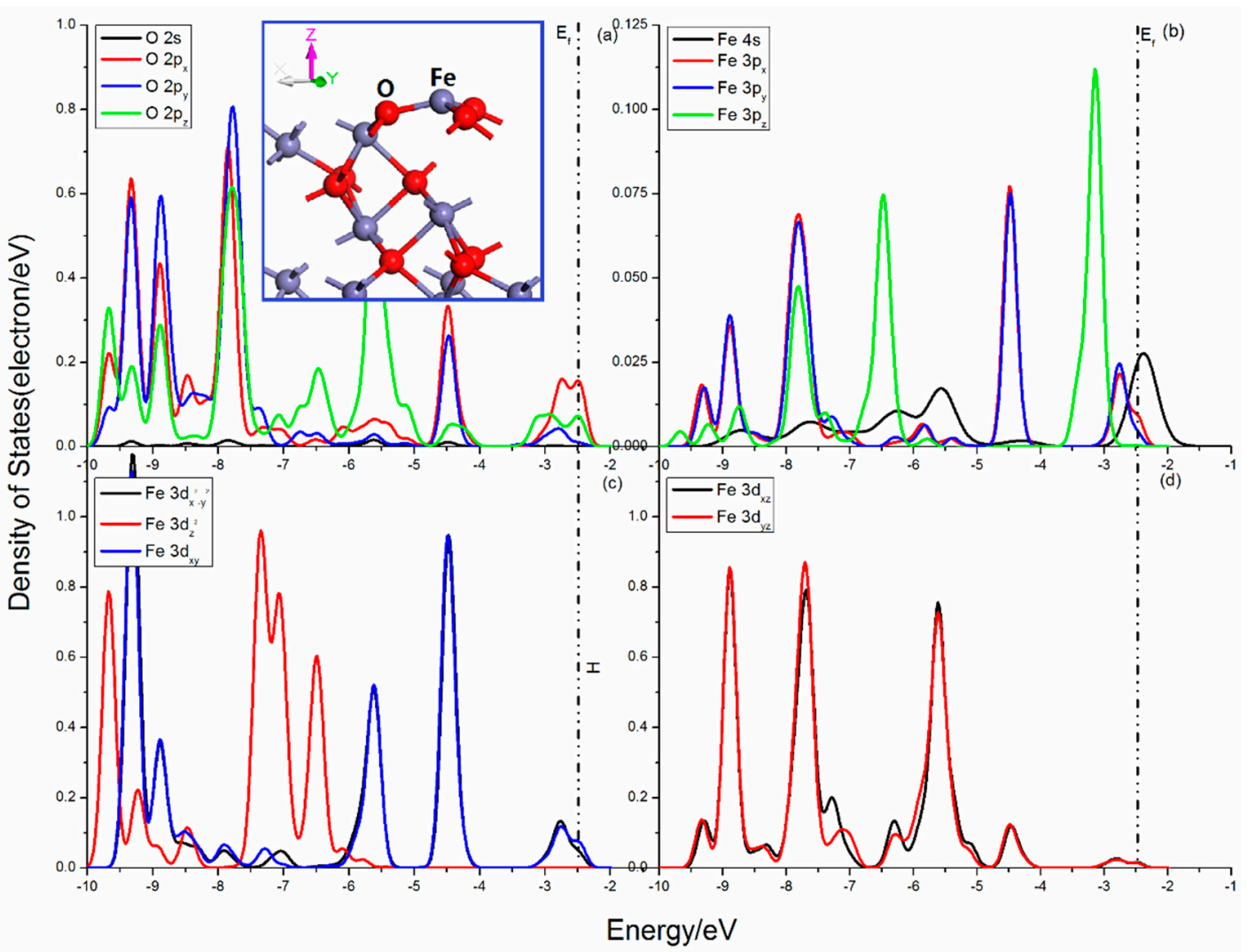

Figure 3. Projected DOSs of $\mathrm{O}$ and Fe for hematite (001) surface: (a) $\mathrm{O} 2 \mathrm{~s}, 2 \mathrm{p}_{\mathrm{x}}, 2 \mathrm{p}_{\mathrm{y}}$ and $2 \mathrm{p}_{\mathrm{z}}$ states; (b) Fe $4 \mathrm{~s}, 3 \mathrm{p}_{\mathrm{x}}, 3 \mathrm{p}_{\mathrm{y}}$ and $3 \mathrm{p}_{\mathrm{z}}$ states; (c) Fe $3 \mathrm{~d}_{\mathrm{x}}{ }^{2}-\mathrm{y}^{2}, 3 \mathrm{~d}_{\mathrm{z}}{ }^{2}$ and $3 \mathrm{~d}_{\mathrm{xy}}$ states; (d) Fe $3 \mathrm{~d}_{\mathrm{xz}}$ and $3 \mathrm{~d}_{\mathrm{yz}}$ states. 
The Femi level situates at $-2.469 \mathrm{eV}$. The interactions of $\mathrm{O}$ and Fe are mainly in the valence band areas, and the sharp mixing peaks attributing to $\mathrm{O} 2 \mathrm{p}$ and $\mathrm{Fe} 3 \mathrm{p}, 3 \mathrm{~d}$, and 4 s orbitals show more characteristic of localization. Significant bonding interactions are located in the range from -8.25 to $-7.25 \mathrm{eV}$, from -6.25 to $-4.75 \mathrm{eV}$ and from -3.5 to $-2.0 \mathrm{eV}$, which is contributed by $\mathrm{O} 2 \mathrm{p}$ and $3 \mathrm{~d}_{\mathrm{zx}}, 3 \mathrm{~d}_{\mathrm{zy}}$ states, O $2 \mathrm{pz}$, and Fe $3 \mathrm{~d}_{\mathrm{x}}{ }^{2}-\mathrm{y}^{2}, 3 \mathrm{~d}_{\mathrm{xy}}, 3 \mathrm{~d}_{\mathrm{yz}}, 3 \mathrm{~d}_{\mathrm{xz}}$, states as well as $\mathrm{O} 2 \mathrm{p}_{\mathrm{x}}, 2 \mathrm{p}_{\mathrm{z}}$, and Fe $3 \mathrm{~d}_{\mathrm{x}}{ }^{2}-\mathrm{y}^{2}, 3 \mathrm{~d}_{\mathrm{xy}}$ states.

\subsubsection{Surface Properties of Galena (100) and Cerussite (110) Surfaces}

Figure 4 shows the projected DOSs of $\mathrm{S}$ and $\mathrm{Pb}$ atoms in the galena (100) surface. For the central S atom, the only broken bond is along the $z$-direction, which has less influence on the $x-y$ plane. For the S 3p states, the $3 p_{x}$ and $3 p_{y}$ states have little split and are equivalent states, as they show the same feature, while the $3 p_{z}$ state is significantly split and its peaks in the upper valence band is quite high and sharp, indicating its great activity. The bond breakage in the $\mathrm{Pb}$ center is similar to that in the $\mathrm{S}$ atom. The $\mathrm{Pb}$ 6s state is broadened and more delocalization, and its curves cover in the range from $-7.5 \mathrm{eV}$ to $-5.0 \mathrm{eV}$ and from $3.5 \mathrm{eV}$ to $6.7 \mathrm{e} \mathrm{V}$. Three $\mathrm{Pb} 6 \mathrm{p}$ states show same curve outlines, which means that the $6 p_{x}, 6 p_{y}$, and $6 p_{z}$ states are also degenerate orbitals, and their DOS are located in the range from $-0.75 \mathrm{eV}$ to $2.10 \mathrm{eV}$ and from $5.50 \mathrm{eV}$ to $7.30 \mathrm{eV}$.

The interactions between $\mathrm{S}$ and $\mathrm{Pb}$ are mainly from the contribution of the $\mathrm{S} 3 \mathrm{~s}, 3 \mathrm{p}$, and $\mathrm{Pb} 6 \mathrm{p}$ states. The bonding mixings distribute in the range from $-0.75 \mathrm{eV}$ to $2.10 \mathrm{eV}$, while the antibonding interactions are located in the energy range from $5.50 \mathrm{eV}$ to $7.30 \mathrm{eV}$. In addition, there still exist unpaired $\mathrm{Pb} 6$ s states near Femi level.

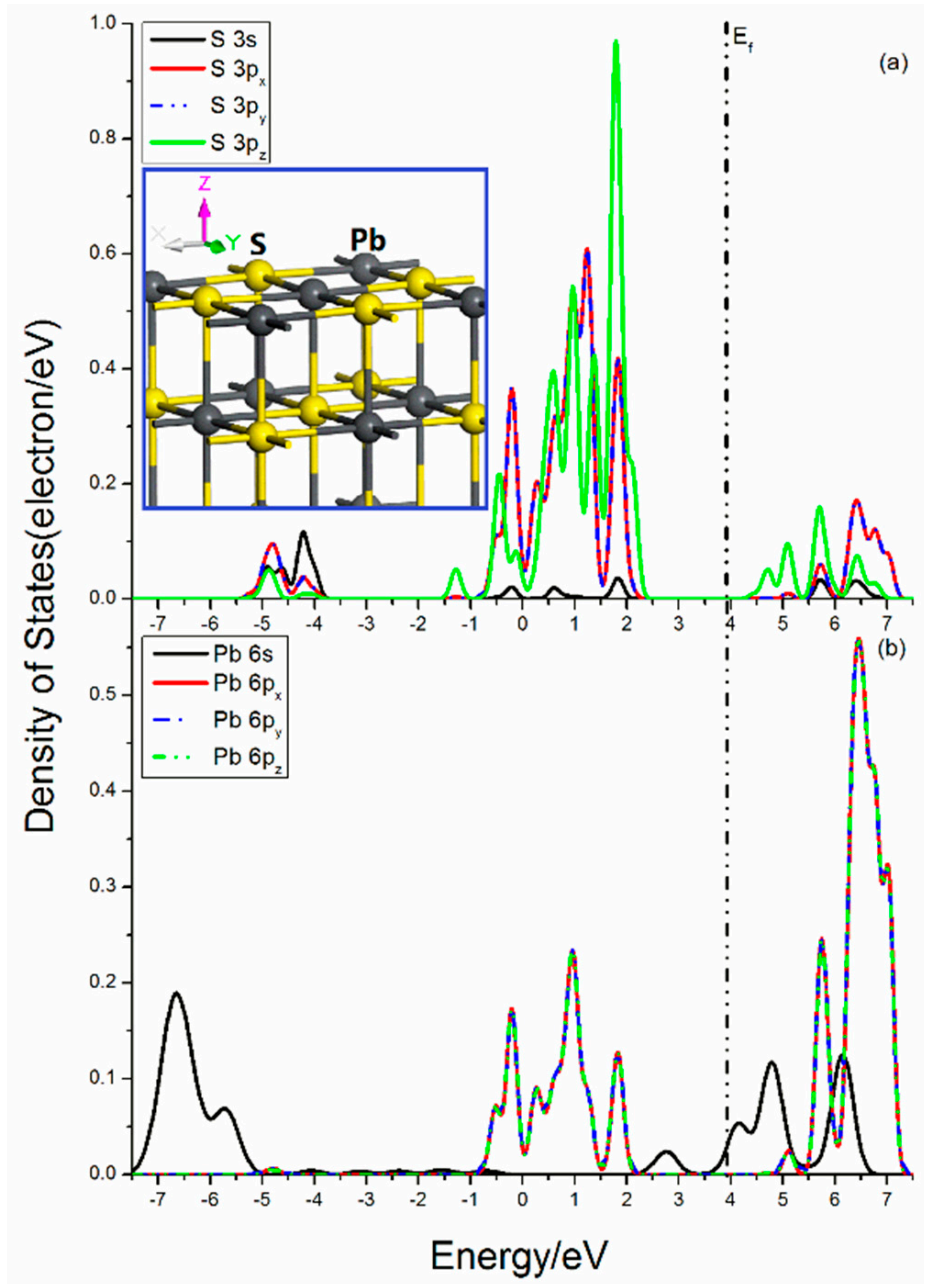

Figure 4. Projected DOSs of $S$ and $\mathrm{Pb}$ of galena (100) surface: (a) $\mathrm{S} 3 \mathrm{~s}, 3 \mathrm{p}_{\mathrm{x}}, 3 \mathrm{p}_{\mathrm{y}}$ and $3 \mathrm{p}_{\mathrm{z}}$ states; (b) $\mathrm{Pb} 6 \mathrm{~s}$, $6 \mathrm{p}_{\mathrm{x}}, 6 \mathrm{p}_{\mathrm{y}}$ and $6 \mathrm{p}_{\mathrm{z}}$ states. 
Figure 5 shows the projected DOSs of $\mathrm{O}$ and $\mathrm{Pb}$ atoms in the cerussite (110) surface. There is only one $\mathrm{O}-\mathrm{Pb}$ bond broken in the $\mathrm{O}$ center. The $\mathrm{O} 2 \mathrm{p}$ states are disturbed heavily, and the $2 \mathrm{p}_{\mathrm{x}}, 2 \mathrm{p}_{\mathrm{y}}$, and $2 \mathrm{p}_{\mathrm{z}}$ states show rather different distributions. There are significantly peaks contributed by $2 p_{y}$ and $2 p_{z}$ states near Femi level, which implies the activity in the $x$ and $z$ direction. The broken $\mathrm{O}-\mathrm{Pb}$ bonds in the $\mathrm{Pb}$ atoms is 3. It is found that the splitting of $\mathrm{Pb} 6$ s states is not so significant with three apparent DOS peaks in the range from $-10 \mathrm{eV}$ to $-6.25 \mathrm{eV}$. The $\mathrm{Pb} 6 \mathrm{p}_{\mathrm{x}}, 6 \mathrm{p}_{\mathrm{y}}$, and $6 \mathrm{p}_{\mathrm{z}}$ states are notably split and the peaks from $2 p_{x}, 2 p_{y}$, and $2 p_{z}$ states show different distributions, and the $2 p_{z}$ state has a peak near Femi level, but not that high and sharp.

The bonding and antibonding interactions are mainly contributed by $\mathrm{O} 2 \mathrm{p}$ and $\mathrm{Pb} 6 \mathrm{p}$ states in the range from -10 to $0.5 \mathrm{eV}$. The bonding mixing peaks attributing by $\mathrm{O} 2 \mathrm{p}$ and $\mathrm{Pb} 6 \mathrm{p}$ states in the upper valence band near Femi level are very strong. Meanwhile, the obvious localization of the O $2 \mathrm{p}$ and $\mathrm{Pb}$ $6 \mathrm{p}$ states indicate that the interaction of $\mathrm{O}$ and $\mathrm{Pb}$ has more ionic bond characteristics.

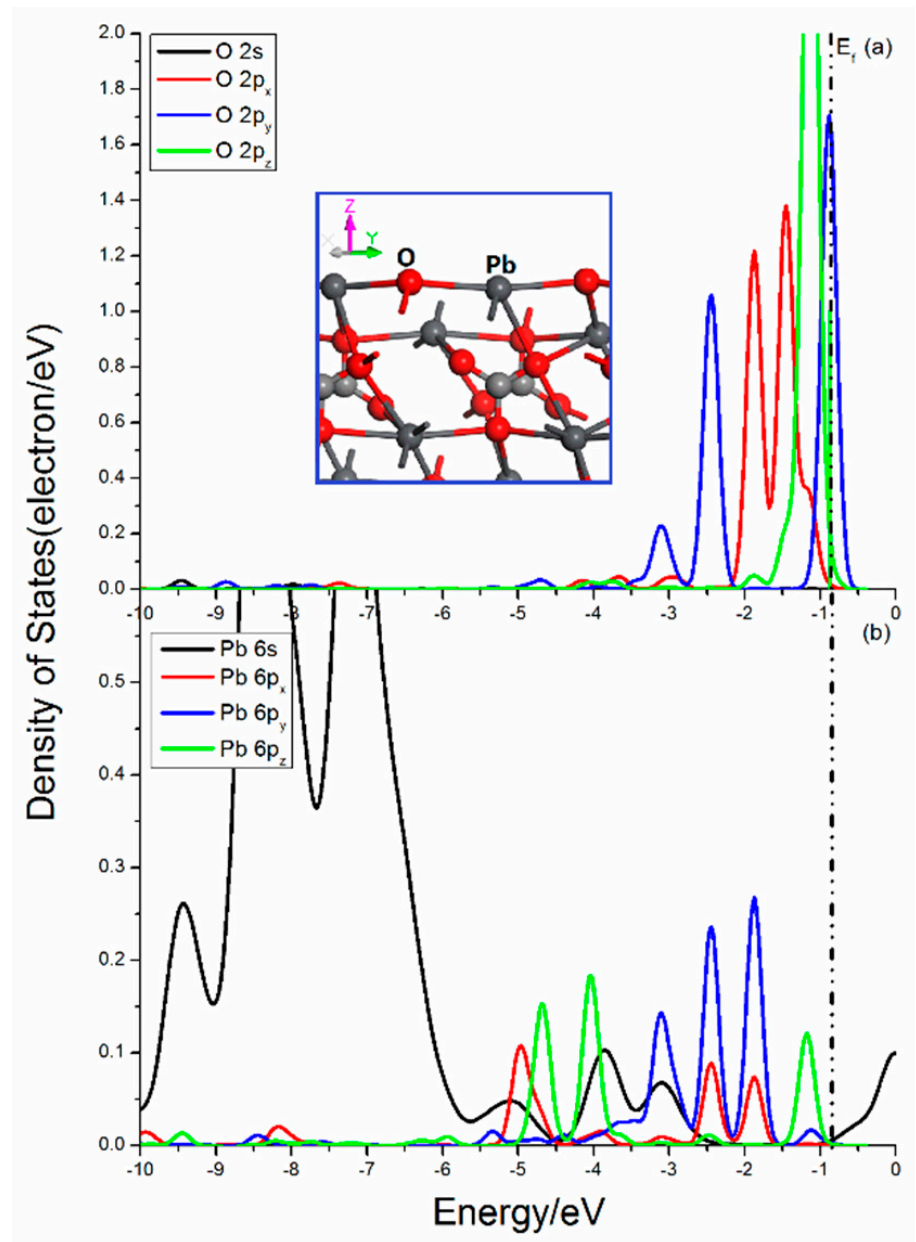

Figure 5. Projected DOSs of $\mathrm{O}$ and $\mathrm{Pb}$ of cerussite (110) surface: (a) $\mathrm{O} 2 \mathrm{~s}, 2 \mathrm{p}_{\mathrm{x}}, 2 \mathrm{p}_{\mathrm{y}}$ and $2 \mathrm{p}_{\mathrm{z}}$ states; (b) $\mathrm{Pb}$ $6 s, 6 p_{x}, 6 p_{y}$ and $6 p_{z}$ states.

\subsubsection{Surface Properties of Sphalerite (110) and Smithsonite (101) Surfaces}

The projected DOSs of $S$ and $Z n$ atoms in the sphalerite (101) surface are shown in Figure 6. The broken S-Zn bond of the S atom make the S 3p orbitals no longer balanced. As shown in Figure 6a, there are significant split of the $S 3 p$ states, and the $3 p_{y}$ state shows a dramatic difference with the $3 p_{x}$ and $3 p_{z}$ states. For the $3 p_{x}$ and $3 p_{z}$ states, their curves cover from -5.5 to $1.0 \mathrm{eV}$ and the important peaks scatter in the range from -0.25 to $1.0 \mathrm{eV}$. Meanwhile, the DOS of $3 p_{y}$ state expands from -5.0 to $1.5 \mathrm{eV}$ and its sharp peaks locate in the range from -3.0 to $-1.0 \mathrm{eV}$ and from 1.0 to $1.5 \mathrm{eV}$. For the $\mathrm{Zn}$ center, the $\mathrm{sp}^{3}$ hybrid orbitals are unbalanced, which will cause a series of changes of the electronic 
cloud distribution. Figure $6 \mathrm{~b}$ shows obvious divisions of the $\mathrm{Zn} 3 \mathrm{p}$ states. The $\mathrm{Zn} 3 \mathrm{p}_{\mathrm{x}}, 3 \mathrm{p}_{\mathrm{z}}$ states present continuous distribution in the range from $-2.0 \mathrm{eV}$ to $1.0 \mathrm{eV}$. The split $\mathrm{Zn} 3 \mathrm{p}_{\mathrm{y}}$ states seems apparent difference and its DOS curve continuous from $-1.8 \mathrm{eV}$ to $1.5 \mathrm{eV}$, with a sharp peak next to Femi level. The five $\mathrm{Zn} 3 \mathrm{~d}$ states exhibit great difference, but have little effect on the S-Zn bonds.

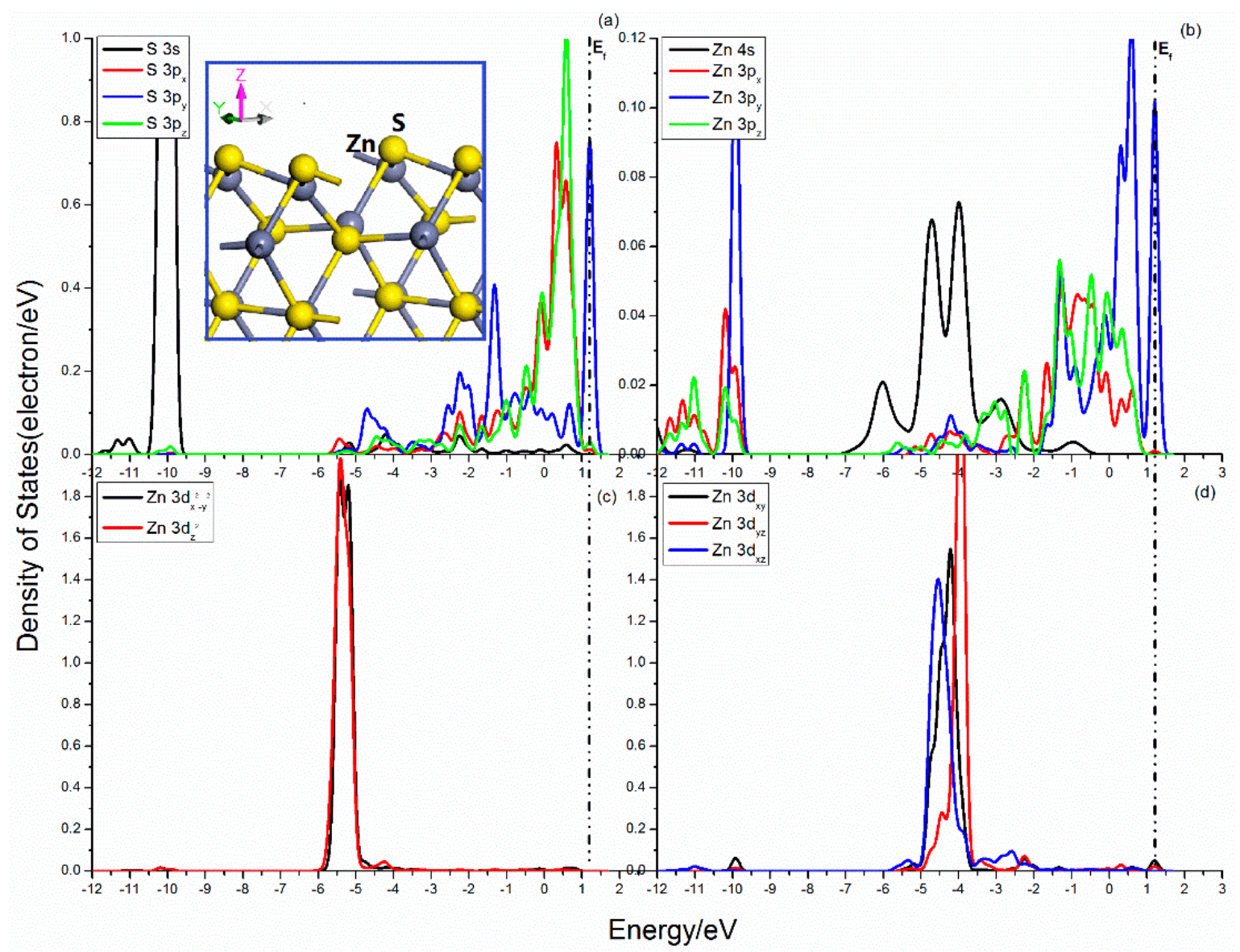

Figure 6. Projected DOSs of $S$ and $Z n$ of sphalerite (110) surface: (a) $S 3 s, 3 p_{x}, 3 p_{y}$ and $3 p_{z}$ states; (b) $Z n$ $4 \mathrm{~s}, 3 \mathrm{p}_{\mathrm{x}}, 3 \mathrm{p}_{\mathrm{y}}$ and $3 \mathrm{p}_{\mathrm{z}}$ states; (c) $\mathrm{Zn} 3 \mathrm{~d}_{\mathrm{x}}{ }^{2}-\mathrm{y}{ }^{2}$ and $3 \mathrm{~d}_{\mathrm{z}}{ }^{2}$ states; (d) $\mathrm{Zn} 3 \mathrm{~d}_{\mathrm{xy}}, 3 \mathrm{~d}_{\mathrm{xz}}$ and $3 \mathrm{~d}_{\mathrm{yz}}$ states.

The bonding and antibonding interactions are distributed in the range from -12.0 to $1.5 \mathrm{eV}$. The bonding interactions among $S 3 s, 3 p$, and $Z n 3 p$ states are provided by $S 3 s$ and $Z n 3 p_{x}, 3 p_{y}, 3 p_{z}$ states in the range from $-12.0 \mathrm{eV}$ to $-9.7 \mathrm{eV}$ and $\mathrm{S} 3 \mathrm{p}_{\mathrm{x}}, 3 \mathrm{p}_{\mathrm{y}}, 3 \mathrm{p}_{\mathrm{z}}$ and $\mathrm{Zn} 3 \mathrm{p}_{\mathrm{x}}, 3 \mathrm{p}_{\mathrm{y}}, 3 \mathrm{p}_{\mathrm{z}}$ states in the energy range from $-3.0 \mathrm{eV}$ to $1.25 \mathrm{eV}$.

The Projected DOSs of O and $\mathrm{Zn}$ atoms in the smithsonite (101) surface are shown in Figure 7. Compared with the sphalerite (110) surface, the DOSs of smithsonite (101) surface shows more electron distribution in the lower energy area. The three curves of the $\mathrm{O} 2 \mathrm{p}$ states are quite different, which indicates that they are split heavily. The $2 p_{x}$ state expands and becomes wider, while the $2 p_{y}$ and $2 p_{z}$ seems more localization, the peaks of the $2 p_{z}$ state in the Femi energy are sharp. The $\mathrm{Zn}$ center shows a sp ${ }^{3}$ hybrid orbitals, when the $\mathrm{O}-\mathrm{Zn}$ bond is broken, the corresponding electron cloud interactions will change. Figure $7 \mathrm{~b}$ shows the $3 p_{x}, 3 p_{y}$, and $3 p_{z}$ states scatter in the range from -11.5 to $0.5 \mathrm{eV}$, and seldom DOS distributes near Femi level except for the tiny peaks attributing to $3 p_{x}$ and $3 p_{z}$ states. Meanwhile, the five $3 \mathrm{~d}$ states are split significantly, and show complex differentiation in the range from $-12.5 \sim-10 \mathrm{eV}$ and from -9.5 to $-2.5 \mathrm{eV}$. 


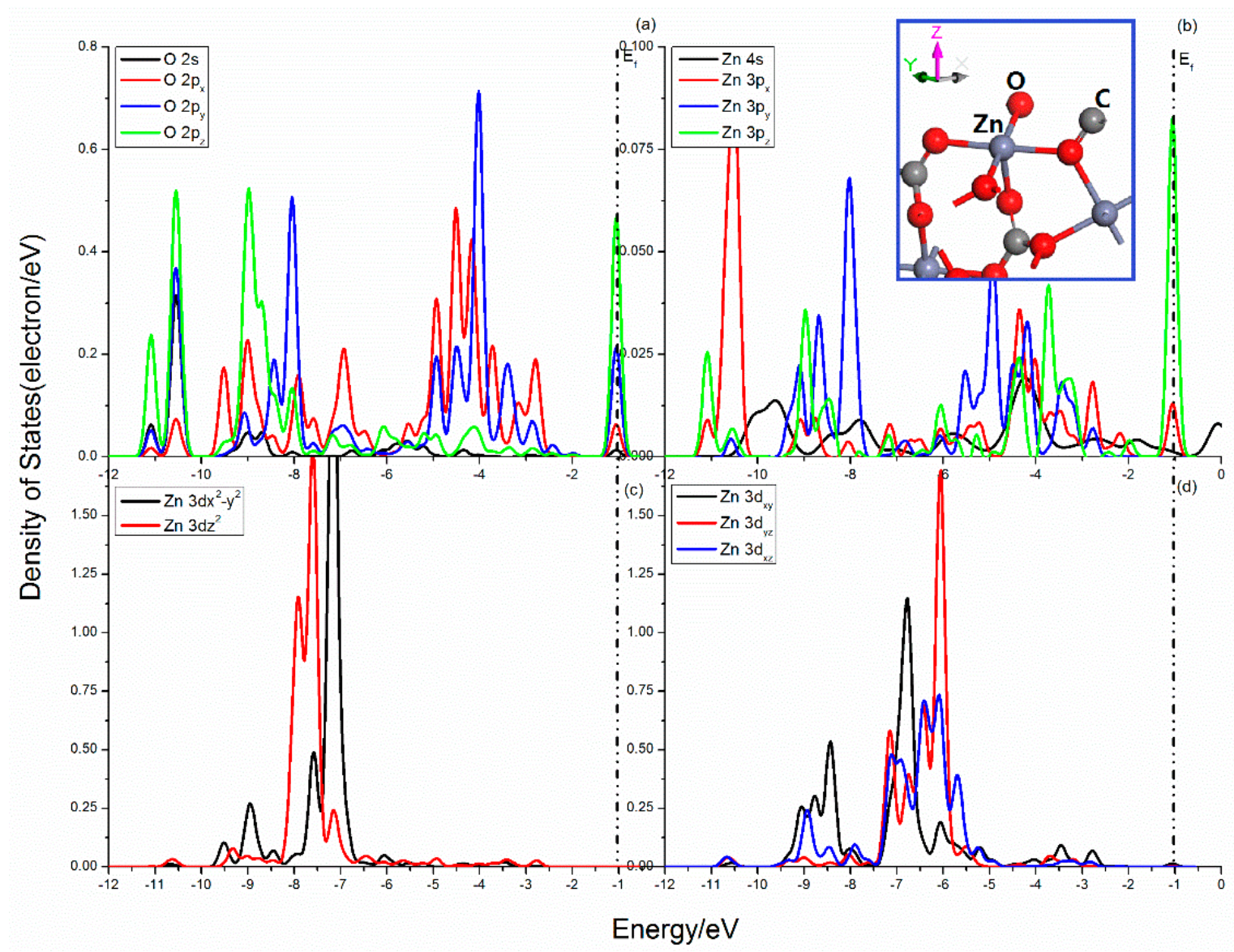

Figure 7. Projected DOS of $\mathrm{O}$ and $\mathrm{Zn}$ of smithsonite (101) surface: (a) $\mathrm{O} 2 \mathrm{~s}, 2 \mathrm{p}_{\mathrm{x}}, 2 \mathrm{p}_{\mathrm{y}}$ and $2 \mathrm{p}_{\mathrm{z}}$ states; (b) Zn $4 \mathrm{~s}, 3 \mathrm{p}_{\mathrm{x}}, 3 \mathrm{p}_{\mathrm{y}}$ and $3 \mathrm{p}_{\mathrm{z}}$ states; (c) $\mathrm{Zn} 3 \mathrm{~d}_{\mathrm{x}}{ }^{2}{ }_{\mathrm{y}}{ }^{2}$ and $3 \mathrm{~d}_{\mathrm{z}}{ }^{2}$ states; (d) $\mathrm{Zn} 3 \mathrm{~d}_{\mathrm{xy}}, 3 \mathrm{~d}_{\mathrm{xz}}$ and $3 \mathrm{~d}_{\mathrm{yz}}$ states.

The complex interactions of $\mathrm{O}$ and $\mathrm{Zn}$ atoms mainly attribute to $\mathrm{O} 2 \mathrm{p}$ and $\mathrm{Zn} 3 \mathrm{p}$ and $3 \mathrm{~d}$ states in the range from -11.5 to $-0.5 \mathrm{eV}$. The bonding states locate in the range from -11.5 to $-10.25 \mathrm{eV}$, from -9.75 to $-8.5 \mathrm{eV}$, and -5.5 to $1.25 \mathrm{eV}$, and contribute by $\mathrm{O} 2 \mathrm{~s}, 2 \mathrm{p}$ and $\mathrm{Zn} 3 \mathrm{p}$, 3d states, $\mathrm{O} 2 \mathrm{p}$ and $\mathrm{Zn} 3 \mathrm{p}$, $3 d_{x}{ }^{2}-y^{2}$, and $3 d_{x y}$ states, and $O 2 p$ and $Z n 3 p_{x}, 3 p_{z}$, and $3 d_{x y}$ states.

\section{Conclusions}

This study focuses on surface electronic structures of sulfide and oxide minerals. Three pairs of different minerals are presented and the conclusions can be summarized as follows:

(1) The direction and magnitude of the atomic displacements are affected by the surface broken bonds. Generally speaking, the atomic displacements of the sulfide surfaces is larger than that of the oxide surfaces, and the atoms of the sulfide minerals surfaces are more likely to reconstruct.

(2) Femi energy analysis shows that the Femi level of the oxide surfaces is generally less than zero, while that of the sulfide surfaces are positive numbers, which means that the sulfide surfaces possess higher chemical potential and are more likely to be electron donors in reactions.

(3) The projected DOSs investigation shows that the outer electrons are easily affected, and the density of states in the direction of broken bonds show significant splits, especially for their $\mathrm{p}$ and $\mathrm{d}$ states. The S $3 p$ states are the mainly contributing states in the sulfide surface, while that in the oxide surface are $\mathrm{O} 2 \mathrm{p}$ states. The bonds of the sulfide surface have more covalent features and that of the oxide surface are ionic interactions. The DOSs of the oxide surfaces are distributed in the lower energy range, which indicates that the bond interactions of oxide surfaces are more stable. 
Author Contributions: Conceptualization and scheme, J.C.; Data curation, Y.Z. and W.C.; Formal analysis, W.C.; Investigation, W.C., Y.Z., J.C., C.Z., Y.L. and Y.C.; Project administration, J.C.; Software, M.-H.L.; Writing一original draft, W.C.

Funding: This research is financially supported by the Natural Science Foundation of China (No. 51574092, 51874106) and the Found of State Key Laboratory of Mineral Processing (BGRIMM-KJSKL-2017-03).

Conflicts of Interest: The authors declare no conflict of interest.

\section{References}

1. Lakshmanan, V.I.; Roy, R.; Ramachandran, V. Innovative process development in metallurgical industry: Concept to commission; Springer: Cham, Switzerland, 2016; pp. 1-140. [CrossRef]

2. Zhao, L.I.; Chen, M.; Huang, P.W.; Zhang, Q.W.; Song, S.X. Effect of grinding with sulfur on surface properties and floatability of three nonferrous metal oxides. Trans. Nonferr. Met. Soc. China 2017, 27, 2474-2480.

3. Kraushofer, F.; Jakub, Z.; Bichler, M.; Hulva, J.; Drmota, P.; Weinold, M.; Schmid, M.; Setvin, M.; Diebold, U.; Blaha, P.; et al. Atomic-Scale Structure of the Hematite $\alpha-\mathrm{Fe}_{2} \mathrm{O}_{3}(1 \overline{10} 2)$ "R-Cut" Surface. J. Phys. Chem. C 2018, 122, 1657-1669. [CrossRef] [PubMed]

4. Muscat, J.; Klauber, C. A combined ab initio and photoelectron study of galena (PbS). Surf. Sci. 2001, 491, 226-238. [CrossRef]

5. Leiro, J.A.; Mattila, S.S.; Laajalehto, K.J. XPS study of the sulphur 2p spectra of pyrite. Surf. Sci. 2003, 547, 157-161. [CrossRef]

6. Becker, U.; Rosso, K.M.; Hochella, M.F. The proximity effect on semiconducting mineral surfaces: A new aspect of mineral surface reactivity and surface complexation theory? Geochim. Cosmochim. Acta 2001, 65, 2641-2649. [CrossRef]

7. Mcfadzean, B.; Mhlanga, S.S.; O'Connor, C.T. The effect of thiol collector mixtures on the flotation of pyrite and galena. Miner. Eng. 2013, 50, 121-129. [CrossRef]

8. Zheng, X.; Pan, X.; Nie, Z.; Yang, Y.; Liu, L.; Yang, H.; Xia, J. Combined DFT and XPS Investigation of Cysteine Adsorption on the Pyrite (1 00 ) Surface. Minerals 2018, 8, 366. [CrossRef]

9. Feng, Q.; Wen, S.; Deng, J.; Zhao, W. Combined DFT and XPS investigation of enhanced adsorption of sulfide species onto cerussite by surface modification with chloride. Appl. Surf. Sci. 2017, 425, 8-15. [CrossRef]

10. Harmer, S.L.; Goncharova, L.V.; Kolarova, R.; Lennard, W.N.; Muñoz-Márquez, M.A.; Mitchell, I.V.; Nesbitt, H.W. Surface structure of sphalerite studied by medium energy ion scattering and XPS. Surf. Sci. 2007, 601, 352-361. [CrossRef]

11. Boulton, A.; Fornasiero, D.; Ralston, J. Characterisation of sphalerite and pyrite flotation samples by XPS and ToF-SIMS. Int. J. Miner. Process. 2003, 65, 205-219. [CrossRef]

12. Kiejna, A.; Pabisiak, T. Effect of substrate relaxation on adsorption energies: The example of $\alpha-\mathrm{Fe}_{2} \mathrm{O}_{3}(0001)$ and $\mathrm{Fe}_{3} \mathrm{O}_{4}(111)$. Surf. Sci. 2019, 679, 225-229. [CrossRef]

13. Han, C.; Li, T.; Zhang, W.; Zhang, H.; Zhao, S.; Ao, Y.; Wei, D.; Shen, Y. Density Functional Theory Study on the Surface Properties and Floatability of Hemimorphite and Smithsonite. Minerals 2018, 8, 542. [CrossRef]

14. Ke, B.; Li, Y.; Chen, J.; Zhao, C.; Chen, Y. DFT study on the galvanic interaction between pyrite (100) and galena (100) surfaces. Appl. Surf. Sci. 2016, 367, 270-276. [CrossRef]

15. von Oertzen, G.U.; Skinner, W.M.; Nesbitt, H.W. Ab initioand x-ray photoemission spectroscopy study of the bulk and surface electronic structure of pyrite (100) with implications for reactivity. Phys. Rev. B 2005, 72, 235427. [CrossRef]

16. Long, X.; Chen, J.; Chen, Y. Adsorption of ethyl xanthate on $\mathrm{ZnS(110)} \mathrm{surface} \mathrm{in} \mathrm{the} \mathrm{presence} \mathrm{of} \mathrm{water}$ molecules: A DFT study. Appl. Surf. Sci. 2016, 370, 11-18. [CrossRef]

17. Jianhua, C.; Baolin, K.; Lihong, L.; Yuqiong, L. DFT and experimental studies of oxygen adsorption on galena surface bearing Ag, Mn, Bi and Cu impurities. Miner. Eng. 2015, 71, 170-179. [CrossRef]

18. Chen, J.; Ke, B.; Lan, L.; Li, Y. Influence of Ag, Sb, Bi and $\mathrm{Zn}$ impurities on electrochemical and flotation behaviour of galena. Miner. Eng. 2015, 72, 10-16. [CrossRef]

19. Chen, J.; Li, Y.; Zhao, C. First principles study of the occurrence of gold in pyrite. Comput. Mater. Sci. 2014, 88, 1-6. [CrossRef]

20. Chen, Y.; Chen, J.; Guo, J. A DFT study on the effect of lattice impurities on the electronic structures and floatability of sphalerite. Miner. Eng. 2010, 23, 1120-1130. [CrossRef] 
21. Chen, Y.; Chen, J. The first-principle study of the effect of lattice impurity on adsorption of CN on sphalerite surface. Miner. Eng. 2010, 23, 676-684. [CrossRef]

22. Hosseini Anvari, M.; Liu, Q.; Xu, Z.; Choi, P. Line tensions of galena (001) and sphalerite (110) surfaces: A molecular dynamics study. J. Mol. Liq. 2017, 248, 634-642. [CrossRef]

23. Feng, Q.; Wen, S.; Deng, J.; Zhao, W. DFT study on the interaction between hydrogen sulfide ions and cerussite (110) surface. Appl. Surf. Sci. 2017, 396, 920-925. [CrossRef]

24. Chen, J.; Long, X.; Ye, C. Comparison of Multilayer Water Adsorption on the Hydrophobic Galena (PbS) and Hydrophilic Pyrite $\left(\mathrm{FeS}_{2}\right)$ Surfaces: A DFT Study. J. Phys. Chem. C 2014, 118, 11657-11665. [CrossRef]

25. Shen, Y.Y.; Zhang, X.D.; Zhang, D.C.; Zhang, L.H.; Liu, C.L. (101)-oriented ZnO nanoparticles fabricated in Si (100) by Zn ion implantation and thermal oxidation. Mater. Lett. 2011, 65, 3323-3326. [CrossRef]

26. Boily, J.-F.; Chatman, S.; Rosso, K.M. Inner-Helmholtz potential development at the hematite $\left(\alpha-\mathrm{Fe}_{2} \mathrm{O}_{3}\right)(001)$ surface. Geochim. Cosmochim. Acta 2011, 75, 4113-4124. [CrossRef]

27. Clark, S.J.; Segall, M.D.; Pickard, C.J.; Hasnip, P.J.; Probert, M.I.J.; Refson, K.; Payne, M.C. First principles methods using CASTEP. Z. für Krist. Cryst. Mater. 2005, 220, 567-570. [CrossRef]

28. Bentarcurt, Y.L.; Calatayud, M.; Klapp, J.; Ruette, F. Periodic density functional theory study of maghemite (001) surface. Structure and electronic properties. Surf. Sci. 2018, 677, 239-253. [CrossRef]

29. Chen, J.-H.; Long, X.-H.; Zhao, C.-H.; Kang, D.; Guo, J. DFT calculation on relaxation and electronic structure of sulfide minerals surfaces in presence of $\mathrm{H}_{2} \mathrm{O}$ molecule. J. Cent. South Univ. 2014, 21, 3945-3954. [CrossRef]

30. Zhang, J.-M.; Pang, Q.; Xu, K.-W.; Ji, V. First-principles study of the (110) polar surface of cubic $\mathrm{PbTiO}_{3}$. Comput. Mater. Sci. 2009, 44, 1360-1365. [CrossRef]

31. Chen, J. The Solid Physics of Sulphide Minerals Flotation; Central South University Press: Changsha, China, 2015.

32. Zhang, S.; Cao, Y. Measure of Redox Potential of Sedimentary Hematite, Siderite and Pyrite and Its Geochemical Significance. J. China Univ. Min. Technol. Chin. Ed. 1992, 2, 59-64. (In Chinese)

33. Herrera-Urbina, R.; Sotillo, F.J.; Fuerstenau, D.W. Effect of sodium sulfide additions on the pulp potential and amyl xanthate flotation of cerussite and galena. Int. J. Miner. Process. 1999, 55, 157-170. [CrossRef]

34. Balichard, K.; Nyikeine, C.; Bezverkhyy, I. Nanocrystalline $\mathrm{ZnCO}_{3}-\mathrm{A}$ novel sorbent for low-temperature removal of $\mathrm{H}_{2}$ S. J. Hazard. Mater. 2014, 264, 79-83. [CrossRef] [PubMed]

35. Holuszko, M.E.; Franzidis, J.P.; Manlapig, E.V.; Hampton, M.A.; Donose, B.C.; Nguyen, A.V. The effect of surface treatment and slime coatings on ZnS hydrophobicity. Miner. Eng. 2008, 21, 958-966. [CrossRef] 